\title{
ONE STEP ELECTROSYNTHESIZED MOLECULARLY IMPRINTED \\ POLYMER ON LASER SCRIBED GRAPHENE BISPHENOL A SENSOR
}

\author{
Tutku Beduk, Abdellatif Ait Lahcen, Nouran Tashkandi, Khaled Nabil Salama*
}

Sensors Lab, Advanced Membranes and Porous Materials Center, Computer, Electrical and Mathematical Science and Engineering Division, King Abdullah University of Science and Technology (KAUST), Thuwal 23955-6900, Saudi Arabia

* Corresponding author. E-mail address: khaled.salama@kaust.edu.sa ; Phone: +9662-808-4420

\section{SUPPLAMENTARY INFORMATION}

\section{Optimization of the LSG fabrication conditions}

Laser-scribed graphene enables the modification of the polyimide structure into 3D porous graphene structure that exhibits a high electrical conductivity. Overall, no graphene formation occurs at $2 \mathrm{~W}$ for the selected speeds, at 3.2 and $3.5 \mathrm{~W}$ a total conversion into graphene is achieved at 2.8 and $3.2 \mathrm{~cm} / \mathrm{s}$, whereas at 4,5 and $10 \mathrm{~W}$ samples are burnt and no graphene formation occurs.

Table S1. The patterning of 5 x $5 \mathrm{~mm}$ squares on PI substrate was tested with different laser speed and power values.

\begin{tabular}{|c|c|c|c|c|c|c|}
\hline \multirow{2}{*}{\multicolumn{2}{|c|}{$\begin{array}{c}\text { Laser } \\
\text { scribed } \\
\text { graphene } \\
\text { optimization }\end{array}$}} & \multirow[b]{2}{*}{3.2} & \multicolumn{4}{|c|}{ Power (W) } \\
\hline & & & \multirow[t]{2}{*}{3.5} & \multirow[t]{2}{*}{4} & \multirow[t]{2}{*}{5} & 10 \\
\hline \multirow{3}{*}{$\begin{array}{l}\text { Laser } \\
\text { speed } \\
(\mathrm{cm} / \mathrm{s})\end{array}$} & 2.8 & & & & & \\
\hline & 3.2 & & & & & \\
\hline & 5 & & & & & \\
\hline
\end{tabular}


Table S2. Resistivity values for different Laser speed/Power values.

\begin{tabular}{|c|c|}
\hline $\begin{array}{c}\text { Parameters } \\
\text { (Laser } \\
\text { speed/Power) }\end{array}$ & $\begin{array}{c}\text { Resistivity } \\
(\boldsymbol{\Omega} / \text { square })\end{array}$ \\
\hline $3.2 / 5$ & 170 \\
\hline $3.2 / 3.2$ & 55 \\
\hline $2.8 / 3.2$ & 58 \\
\hline $2.8 / 5$ & 118 \\
\hline $5 / 5$ & 133 \\
\hline $5 / 10$ & burnt \\
\hline $3.2 / 4$ & 95 \\
\hline $2.8 / 4$ & 200 \\
\hline $3.2 / 3.5$ & 60 \\
\hline $2.8 / 3.5$ & 60 \\
\hline
\end{tabular}
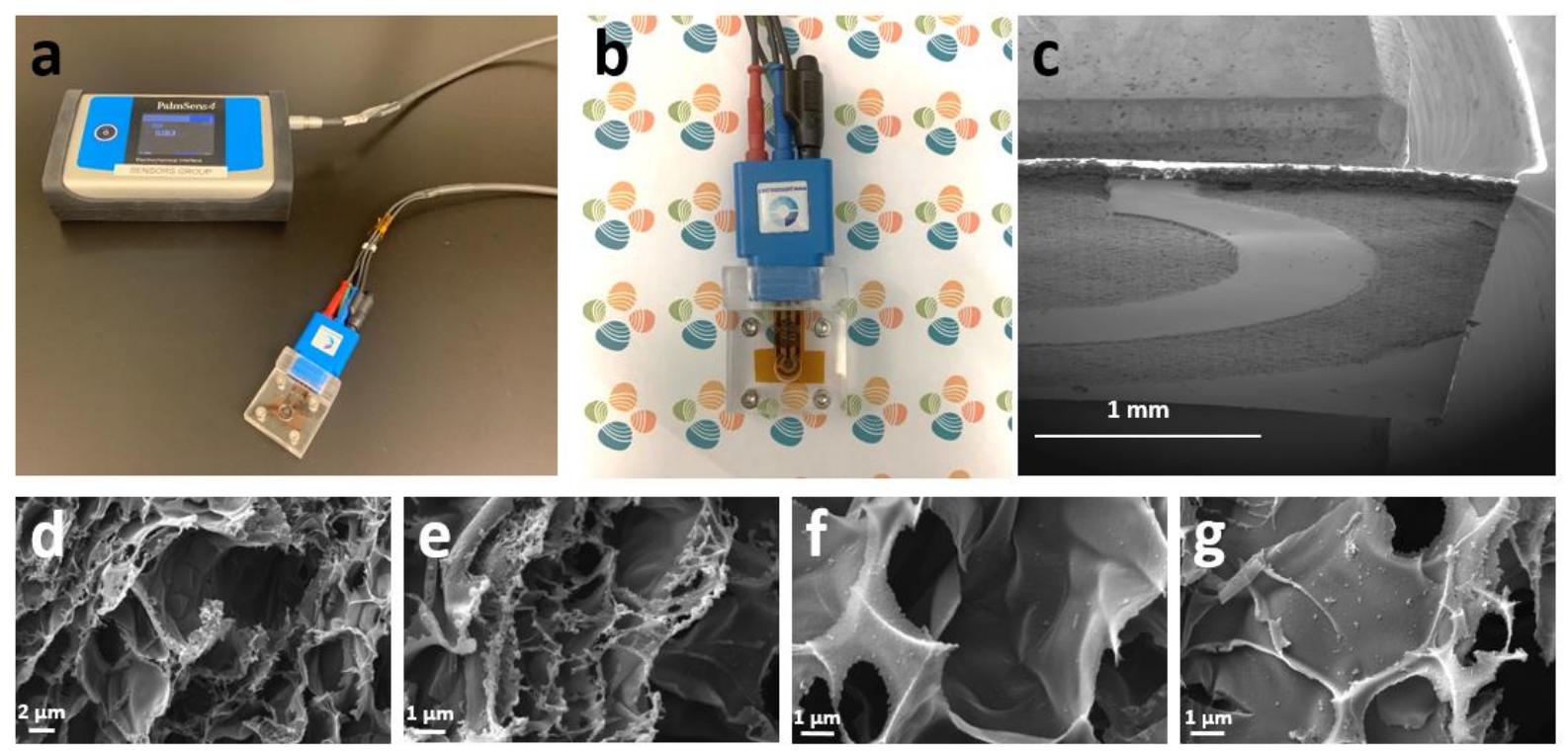

Fig. S1. a), b) The pictures of the device integrated in the PMMA case. c) FESEM image of the LSG electrode. FESEM images of the MIP/Pyr@LSG working electrode d), e) after removing BPA, f), g) after rebinding $1 \mu \mathrm{m}$ BPA. MIP/Pyr@LSG was prepared under the optimal conditions. 


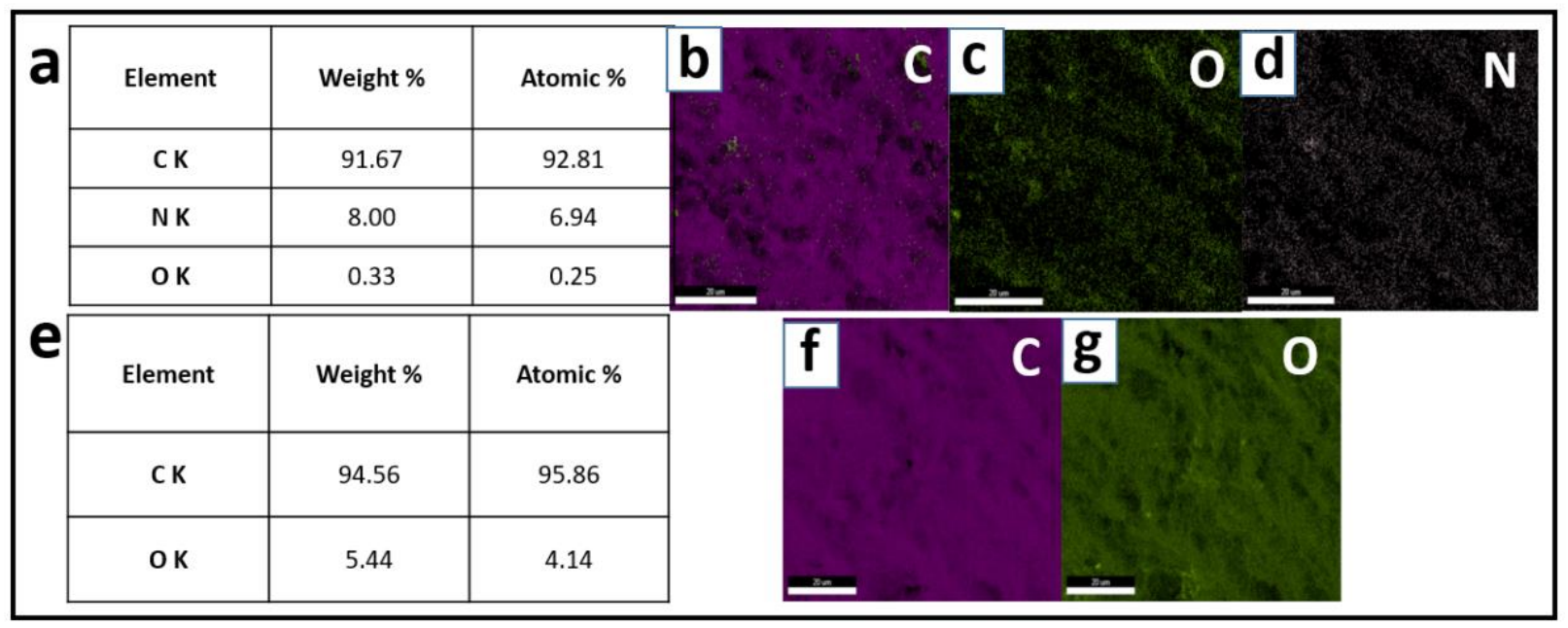

Fig. S2. Energy Dispersive X-Ray Analyzer (EDX) atomic percentage results of LSG electrode a) after pyrrole electropolymerization (prepared by 10 cycles of electropolymerization with $0.2 \mathrm{M}$ pyrrole), e) before pyrrole electropolymerization. Scanning Electrode microscopy (SEM) of b), c), d) $\mathrm{C}, \mathrm{O}$ and $\mathrm{N}$; f), g) $\mathrm{C}$ and $\mathrm{O}$ respectively proving the deposition of pyrrole. 

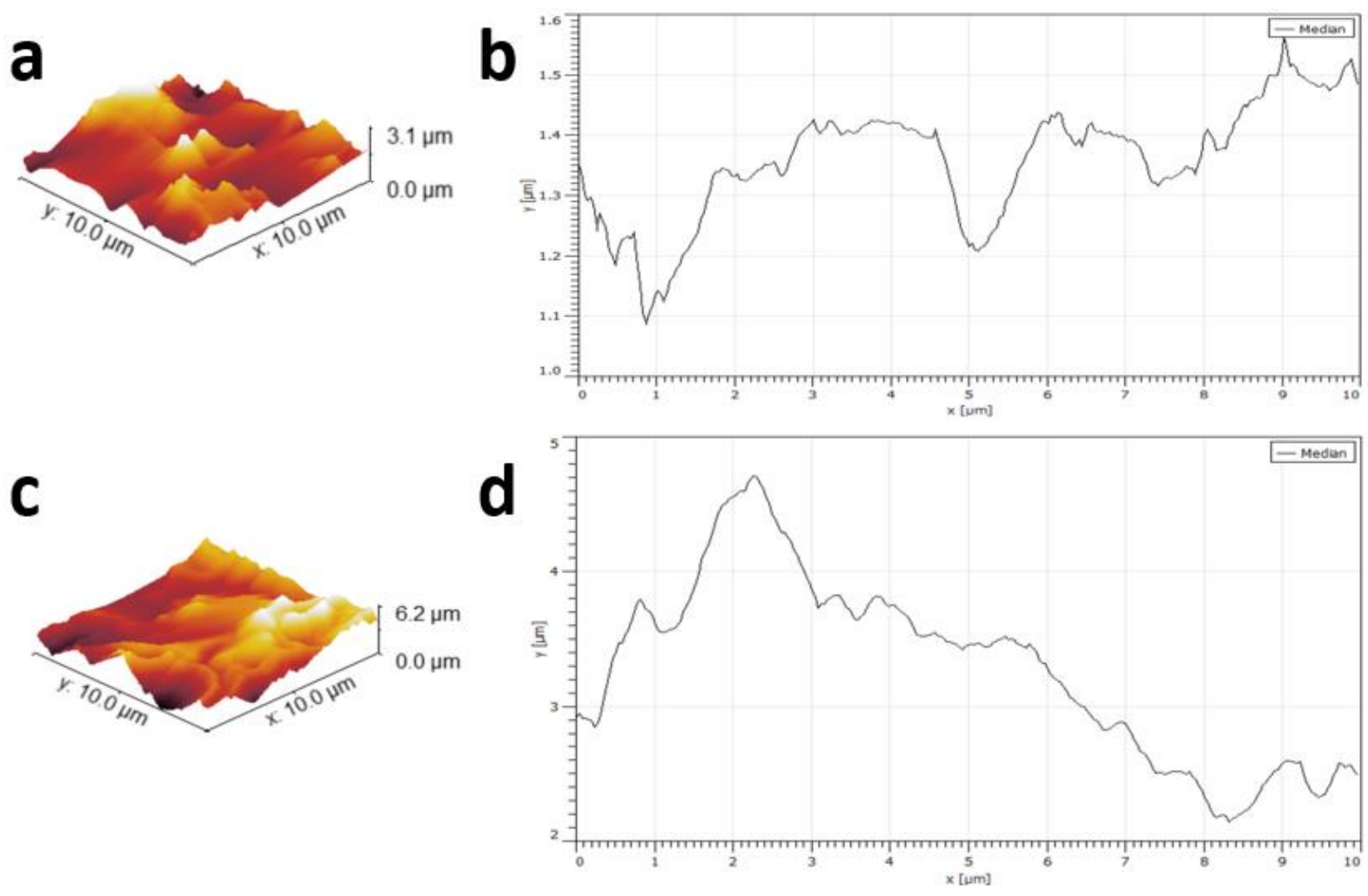

Fig. S3. 3D Atomic Force Microscopy (AFM) images and surface cross section profile of working electrode surfaces: a), b) bare LSG and c), d) PPy@LSG prepared by 10 cycles of electropolymerization with $0.2 \mathrm{M}$ Pyrrole. 

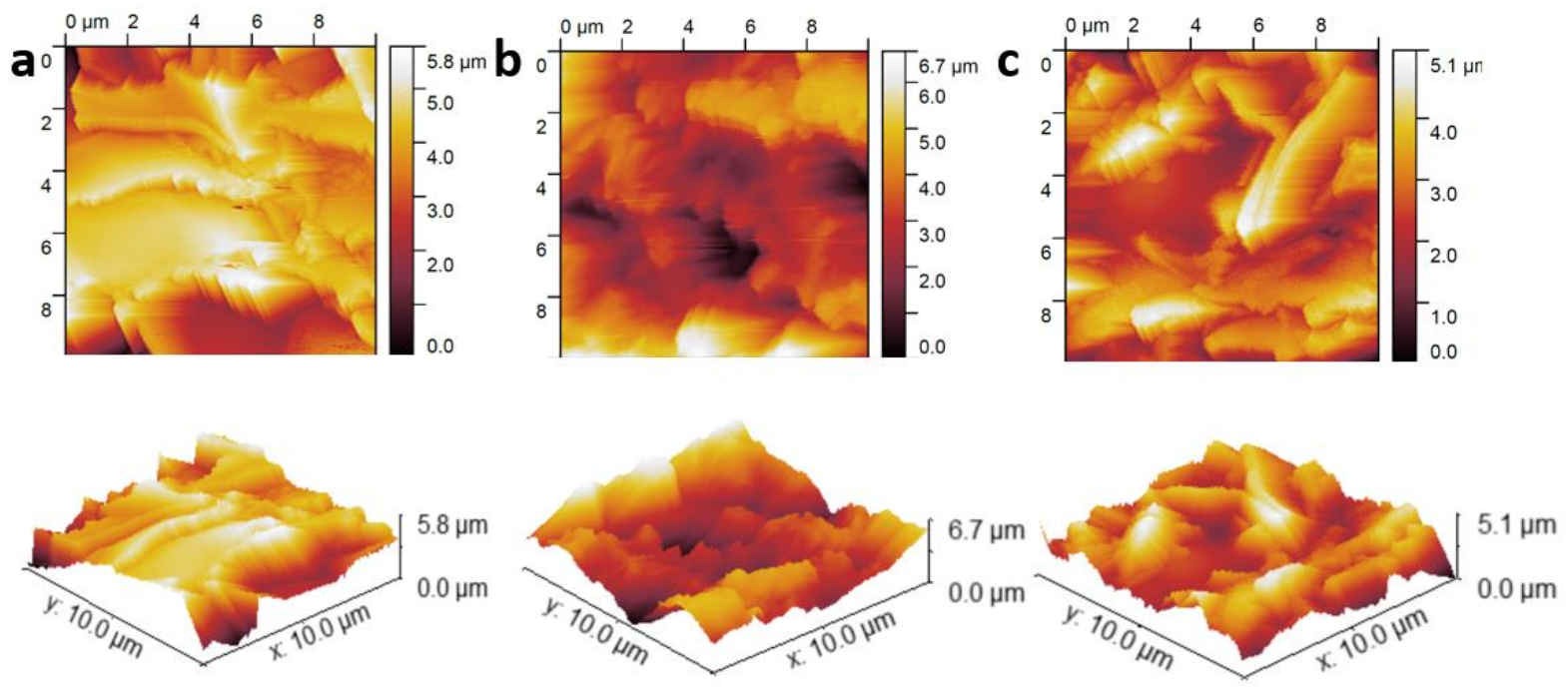

Fig. S4. Atomic Force Microscopy (AFM) images and 3D representation of working electrode surfaces: a) MIP/PPy@LSG adduct, b) MIP/PPy@LSG after removal and c),d) MIP/PPy@LSG after rebinding BPA under optimal conditions.

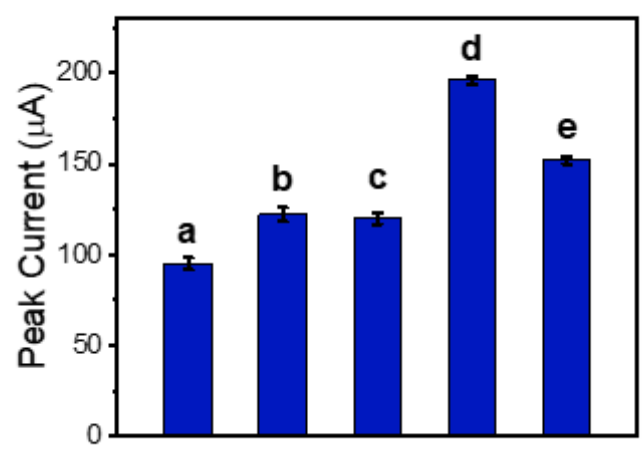

Fig. S5. Oxidation peak currents of a: Bare LSG, b: NIP/PPy@LSG, c: MIP/PPy@LSG adduct, d: MIP/PPy@LSG after removal, e: MIP/PPy@LSG after rebinding of BPA, based on cyclic voltammograms obtained using $0.05 \mathrm{M}\left[\mathrm{Fe}(\mathrm{CN})_{6}\right]_{3}$-in $0.1 \mathrm{M} \mathrm{KCl}$. Scan rate: $100 \mathrm{mV} / \mathrm{s}$. 
Table S3. Oxidation and Reduction current and potential values of Bare LSG, NIP/PPY @LSG, MIP/PPY @LSG Adduct, After removal of BPA, After binding of $1 \mu \mathrm{M}$ BPA. Scan rate: 100mV/s.

\begin{tabular}{|c|c|c|c|c|c|c|}
\hline & $\begin{array}{c}\text { Iox } \\
(\mu \mathrm{A})\end{array}$ & $\begin{array}{c}\text { Ired } \\
(\boldsymbol{\mu A})\end{array}$ & Iox/Ired & $\begin{array}{c}\text { Eox } \\
(\mathrm{mV})\end{array}$ & $\begin{array}{c}\text { Ered } \\
(\mathrm{mV})\end{array}$ & $\begin{array}{c}\text { Eox-Ered } \\
(\mathrm{mV})\end{array}$ \\
\hline Bare LSG & 95 & -93 & 1.02 & 20 & -140 & 160 \\
\hline NIP/PPy@LSG & 122 & -141 & 0.87 & 20 & -190 & 210 \\
\hline $\begin{array}{c}\text { MIP/ PPy@LSG } \\
\text { Adduct }\end{array}$ & 120 & -140 & 0.852 & 10 & -180 & 190 \\
\hline $\begin{array}{c}\text { MIP/PPy@LSG } \\
\text { After removing of } \\
\text { BPA }\end{array}$ & 196 & -210 & 0.931 & 10 & -260 & 270 \\
\hline $\begin{array}{c}\text { MIP/ PPy }(a) L S G \\
\text { After binding of } 1 \\
\mu \text { M BPA }\end{array}$ & 152 & -167 & 0.912 & 20 & -200 & 230 \\
\hline
\end{tabular}

\section{Effect of scan rate}

The effect of scan rate ranging from $20-130 \mathrm{mV} / \mathrm{s}$ on the electrochemical performance of the LSG bare electrode and the MIP/PPy@LSG was also studied as presented in Fig S5. The magnitudes of the current intensity responses (shown in Fig S5a and S5b) and a gradual increment with the increase in the scan rate for both electrodes. The MIP/PPy@LSG sensor showed higher increment in current intensity values due to its high specific surface area. Hence, it was observed that the current intensities depend on the square root of scan rate linearly as shown in Fig S5c and $\mathbf{5 d}$ for LSG sensor following the equations below:

$$
\begin{array}{lllc}
I p a= & 11.69(v)_{1 / 2}-19.33 & R_{2}=0.996 & E \boldsymbol{q}(1)(\text { Bare LSG) } \\
I p c= & -11.17(v)_{1 / 2}+16.79 & R_{2}=0.980 & E q(2)(\text { Bare } L S G) \\
I p a= & 19.41(v)_{1 / 2}-25.99 & R_{2}=0.997 & \boldsymbol{E q}(3)(M I P / P P y @ L S G) \\
I p c= & -18.71(v)_{1 / 2}+22.12 & R_{2}=0.997 & \boldsymbol{E q}(4)(M I P / P P y @ L S G)
\end{array}
$$

In Fig. S5b, Ferricyanide oxidation and reduction peaks were seen clearly with a linear relationship between the square root of scan rate vs. current values suggesting that the process is controlled by diffusion and the ratio of the redox peak is close to 1 . The active surface area of the MIP/PPy/LSG was estimated based on Randles-Sevick equation as presented below: 
Where $D$ is diffusion coefficient $(D=6.70 \times 10-6 \mathrm{~cm} 2 \mathrm{~s}-1), A$ is active surface area of the modified LSG electrode, $C$ is concentration of $[\mathrm{Fe}(\mathrm{CN}) 6]_{3-}(\mathrm{mol} \cdot \mathrm{cm}-3)$, and $v$ is scan rate $(\mathrm{mV} \mathrm{s}-1)$ and $I \mathrm{p}$ is the anodic peak current (A). From the slope of the above equation, the active surface area of the MIP/PPy@LSG was determined as $0.279 \mathrm{~cm} 2$, which is higher than the active surface area of LSG $(0.168 \mathrm{~cm} 2)$. This significant increase in the active surface area is attributed to the highly conducting polymer deposited onto the surface of LSG sensor leading to an increase in term of sensitivity of the sensor.
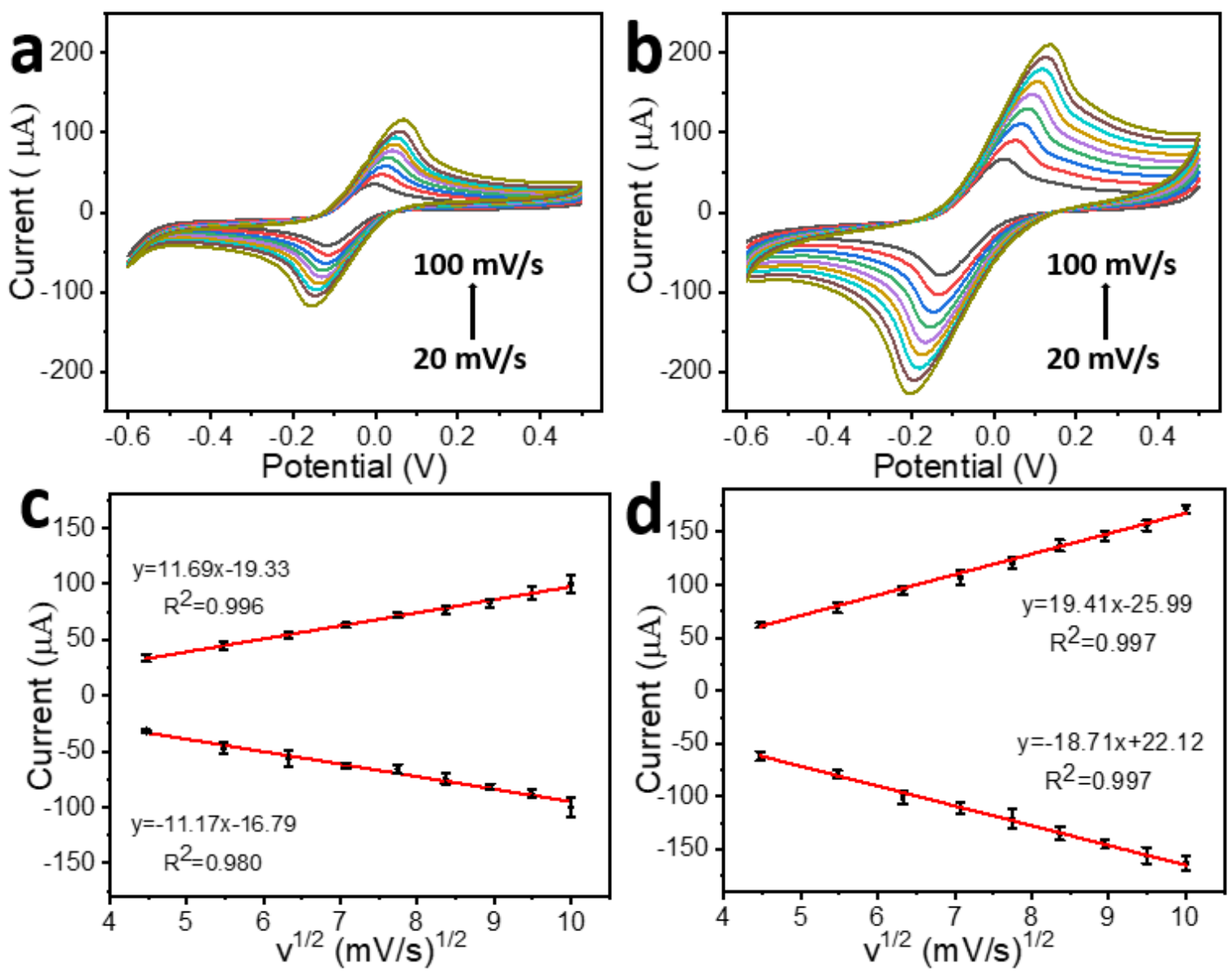

Fig S6. Cyclic voltammograms obtained using $0.05 \mathrm{M}[\mathrm{Fe}(\mathrm{CN}) 6] 3-i n$ 0.1 $\mathrm{M} \mathrm{KCl}$ for (a) LSG device (b) MIP/PPy@LSG (prepared by 10 cycles of electropolymerization with $0.2 \mathrm{M}$ Pyrrole and $1 \mu \mathrm{M}$ BPA) after removal of present BPA, with different scan rates varying from 20 to $130 \mathrm{mV} / \mathrm{s}$. (c) and (d) presents the calibration data of the bare LSG and MIP/PPy@LSG device respectively.

\section{Optimization of number of electropolymerization cycles of NIP/Pyr@LSG}



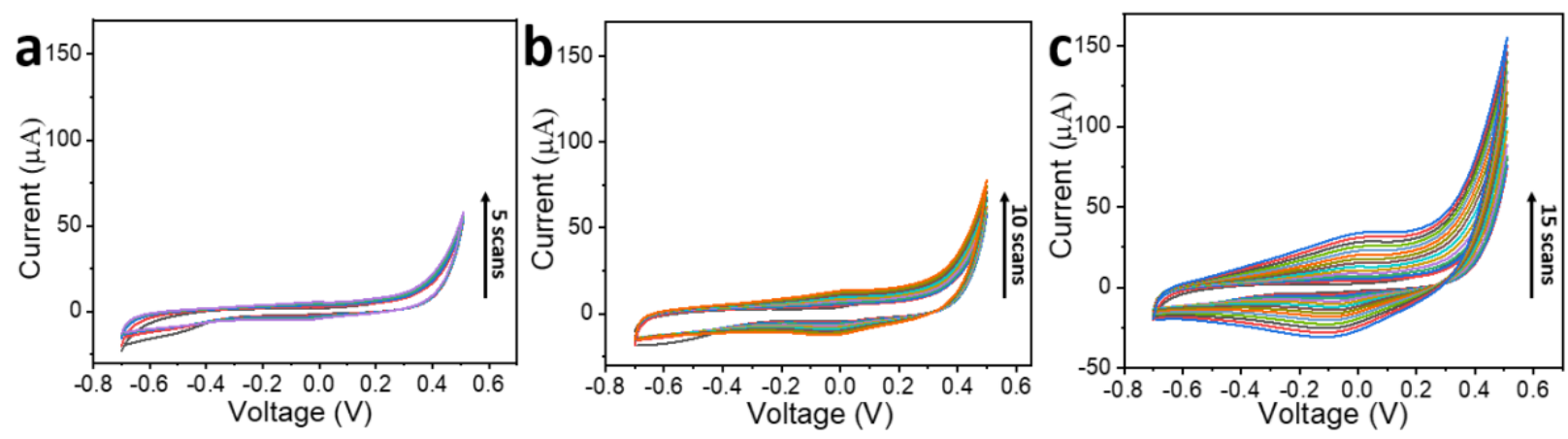

Fig S7. Cyclic Voltamograms representing electropolymerization of NIP/PPy@ LSG electrodes with a) 5 , b) 10 , c) 15 cycles in $0.05 \mathrm{M}$ PBS solution having $0.2 \mathrm{M}$ Pyrrole (scan rate, $50 \mathrm{mV} / \mathrm{s}$ ). 